\title{
Cholinergic modulation of epileptiform activity in the developing rat neocortex
}

\author{
Bernd Sutor* and John J. Hablitz \\ Section of Neurophysiology, Department of Neurology. Baylor College of Medicine, Houston, TX 77030 (U.S.A.)
}

(Accepted 15 November 1988)

Key words: Acetylcholine; Neocortex; Development; Epilepsy; Neuromodulation; Carbachol

\begin{abstract}
The effects of carbachol on picrotoxin-induced epileptiform activity and membrane properties of neurons in the developing rat neocortex were examined in an in vitro slice preparation. Intracellular recordings were obtained in layer II-III neurons of slices prepared from rats 9-21 days of age. Epileptiform activity in 9- to 14-day-olds consisted of a sharply rising, sustained (10-30 s) membrane depolarization with superimposed action potentials. Bath application of carbachol (5-50 $\mu \mathrm{M})$ raised the threshold for evoking epileptiform activity but, when such responses were evoked, their underlying depolarizations were increased in amplitude. Orthodromic stimulation in slices from 15- to 21-day-old animals evoked a prolonged epileptiform burst response that triggered an episode of spreading depression (SD). Carbachol reduced epileptiform responses and suppressed the occurrence of SD. It did not significantly affect the resting membrane potential or the height of the action potential but decreased the rheobase current needed to evoke an action potential and increased the input resistance. All effects of carbachol were antagonized by atropine $(1 \mu \mathrm{M})$. These results indicate that carbachol has both pre- and postsynaptic effects in the developing neocortex and can significantly modulate neuronal excitability in the immature nervous system.
\end{abstract}

Electrophysiological studies in mature neocortex in vivo have repeatedly demonstrated that acetylcholine (ACh) has a predominantly excitatory effect. Iontophoretic application of cholinergic agonists produces, after a delay, an increase in the firing rate of spontaneously active cells ${ }^{18.20 .21}$. ACh enhances discharges evoked by sensory stimuli ${ }^{26}$ and causes previously unresponsive neurons to discharge ${ }^{3}$. Early studies suggested that the excitatory effects of $\mathrm{ACh}$ were seen predominantly in deeper cortical layers ${ }^{18.20 .21}$, but more recent studies have reported cholinergic enhancement of neuronal activity in superficial strata (layer II-III) as well ${ }^{3.24}$. The slow cholinergic excitation of cortical neurons is mediated by receptors with muscarinic properties ${ }^{18}$, although nicotinic $^{30}$ or mixed ${ }^{20.25}$ excitations have been reported. Intracellular recordings in vivo and in vitro have shown that $\mathrm{ACh}$ has a slow depolarizing action that may or may not initiate action potential dis- charge. ACh does, however, markedly potentiate excitatory effects produced by other inputs ${ }^{19}$. In addition to these excitatory effects, ACh also enhances spontaneous epileptiform activity in the neocorte ${ }^{4}$ and penicillin-induced epileptiform discharges in pyramidal neurons of the guinea pig hippocampus ${ }^{16}$.

We have previously used slices of immature rat neocortex to study ontogenetic influences on membrane properties ${ }^{12}$ and responses to convulsant drugs ${ }^{y}$. Although responses to $\mathrm{ACh}$ iontophoresis are seen in rats 9-18 days of age ${ }^{31}$, possible cholinergic influences on synaptically evoked responses and membrane properties of neurons in the developing neocortex have not been extensively explored. This study therefore examined the effect of the cholinergic agonist carbachol on both intrinsic electrical properties and picrotoxin-induced epileptiform activity in the immature neocortex. Our

\footnotetext{
* Present address: Physiologisches Institut der Universität, Pettenkoferstrasse 12, 8000 München 2, F.R.G. Correspondence: J.J. Hablitz, Neurobiology Research Center, University of Alabama at Birmingham, Birmingham, AL 35294 ,
U.S.A.
} 
results indicate that carbachol has marked neuromodulatory actions in the neonatal period. A preliminary account of some of these results has been published previously ${ }^{11}$.

Neocortical slices (400-500 $\mu \mathrm{m}$-thick) were prepared from the anterior frontal cortex of immature rats (9-21 days of age) as described previously ${ }^{9-12}$. The slices were continuously perfused (1.5-2.0 $\mathrm{ml} / \mathrm{min})$ with an oxygenated $\left(\begin{array}{llll}95 \% & \mathrm{O}_{2}-5 \% & \mathrm{CO}_{2}\end{array}\right)$ saline containing (in $\mathrm{mM}$ ): $\mathrm{NaCl}, 124 ; \mathrm{KCl}, 5$; $\mathrm{NaH}_{2} \mathrm{PO}_{4}, 1.25 ; \mathrm{CaCl}_{2}, 2 ; \mathrm{MgSO}_{4}, 2 ; \mathrm{NaHCO}_{3}, 24$; glucose, 10. A moist gas mixture was directed across the surface of the slices, and the temperature was maintained at $33-35{ }^{\circ} \mathrm{C}$. All slices were allowed to equilibrate for a minimum of $1 \mathrm{~h}$ before epileptiform activity was induced by the addition of picrotoxin (50 $\mu \mathrm{M})$ to the perfusate.

Intracellular recordings were obtained from neurons in layer II-III of the cortex, as estimated by the depth below the pial surface. Electrodes were prepared on a Brown-Flaming-type puller using filament-containing glass capillaries. These electrodes had a DC resistance of 50-100 $\mathrm{M} \Omega$ when filled with $4 \mathrm{M}$ potassium acetate. A single-electrode time-share circuit was used for voltage recording and current passage. Membrane potentials were monitored continuously on a chart recorder, while other data were stored on magnetic tape for off-line analysis with a PDP 11/23 + computer.

The input resistance and discharge properties of the neurons were evaluated by passing a series of hyperpolarizing and depolarizing current pulses through the recording electrode. A bipolar platinum stimulating electrode was placed in layer IV for synaptic activation of epileptiform activity. Stimulus intensities are given as the charge applied to the electrode (in $\mathrm{nC}$ ). After control recordings of both spontaneous and evoked paroxysmal activity and responses to current pulses had been obtained, carbachol was bath applied at concentrations of $10-100 \mu \mathrm{M}$. Atropine $(1 \mu \mathrm{M})$ was subsequently bath-applied to test for involvement of muscarinic receptors. Each neuron served as its own control.

The cells $(n=14)$ recorded in this study had an average resting potential of $-69.2 \pm 5.9 \mathrm{mV}$, overshooting action potentials of $82.5 \pm 9 \mathrm{mV}$, and an input resistance of $36.6 \pm 13.8 \mathrm{M} \Omega$. These values are similar to those reported previously for immature neocortical neurons by our group ${ }^{12}$ and by others ${ }^{17}$. There were no significant differences in these parameters between the 9- to 14 and 15-to 21 -day-old animals. All of the neurons studied had the characteristics of regular-spiking cells ${ }^{23}$; no bursting or fast-spiking cells were encountered.

Application of carbachol had no significant effect on the resting membrane potential or height of the action potential in either age group. The most striking effect, in both groups, of low doses of carbachol $(5-50 \mu \mathrm{M})$ was a decrease in the rheobase current needed to evoke an action potential. As

\section{CONTROL}
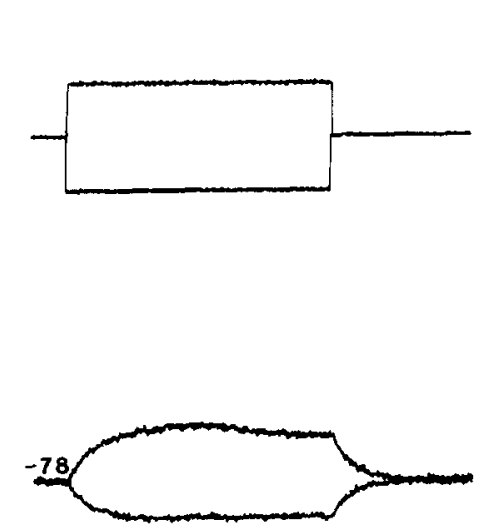

CARBACHOL

5 UM

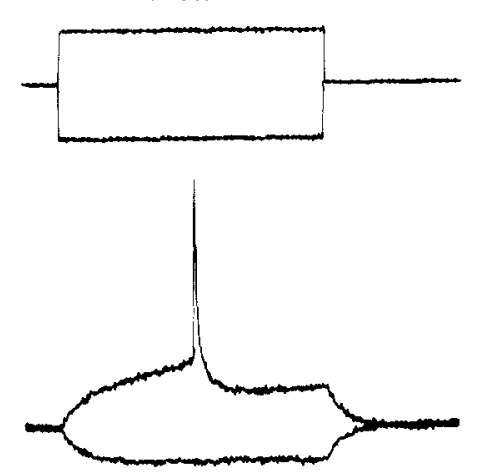

CARBACHOL $100 \mathrm{UM}$

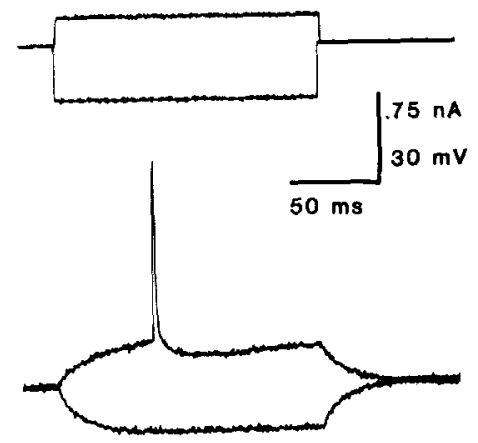

Fig. 1. Dose-dependent effects of carbachol on basic electrical properties of a neuron from a 12-day-old animal. Leftmost traces: control responses to depolarizing and hyperpolarizing current pulses. Middle traces: response to the same current pulses in the presence of $5 \mu \mathrm{M}$ carbachol. Note lowered threshold for action potentials. Rightmost traces: raising the carbachol concentration to $100 \mu \mathrm{M}$ results in an increase in the response to the hyperpolarizing pulse and a further reduction in threshold. Note decrease in the amplitude of the depolarizing pulse. Resting potential was $-78 \mathrm{mV}$. 
A

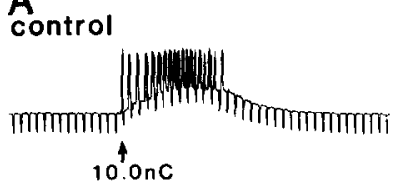

C.ash $27 \mathrm{~min}$

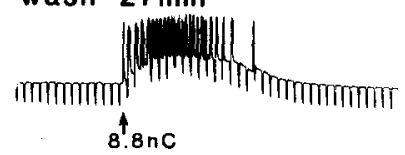

B

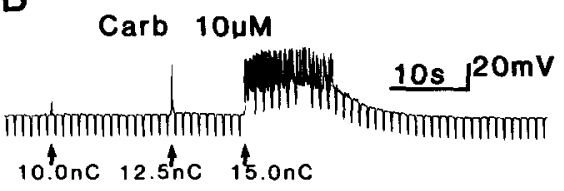

D

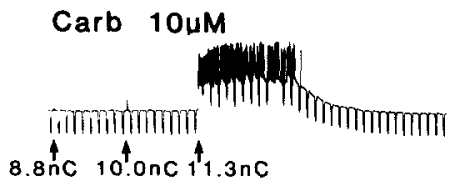

Fig. 2. Effect of cabachol on epileptiform discharges in a neuron from a 9-day-old animal. A: control response to a 10-nC stimulus applied via a stimulating electrode in layer IV. B: response to 3 stimuli of increasing intensity given in the presence of $10 \mu \mathrm{M}$ carbachol. Note the increased amplitude of the depolarization evoked by the 15-nC stimulus. C: record obtained after removal of carbachol shows recovery of ability of low-intensity stimuli to evoke epileptiform activity. D: re-application of carbachol again produces an increase in threshold for evoking a response and an enhancement of the depolarization. Negative deflections are responses to a $0.4-\mathrm{nA}$ hyperpolarizing current pulse. Resting potential was $-66 \mathrm{mV}$.

shown in Fig. 1, a depolarizing current pulse that was subthreshold for eliciting a spike in the control period (Fig. 1; leftmost traces) was able to trigger one after exposure to $5 \mu \mathrm{M}$ carbachol (Fig. 1; middle traces). This occurred without any change in the response to the hyperpolarizing current pulse. When the concentration of cabachol was increased to 100
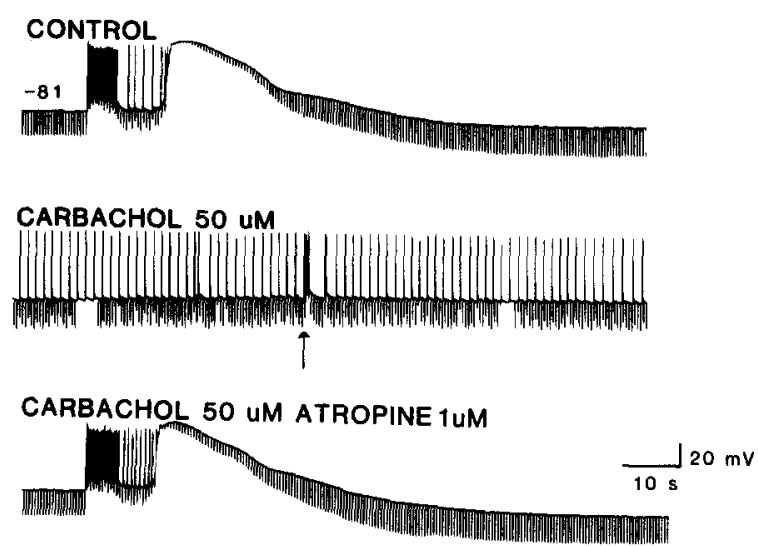

Fig. 3. Action of carbachol on epileptiform activity in a slice from a 17-day-old animal. Upper trace: recording in normal saline containing $50 \mu \mathrm{M}$ picrotoxin. Stimulation at 5-nC evokes an initial prolonged epileptiform burst response, followed by a large depolarization associated with the onset of SD. Middle trace: effect of bath application of $50 \mu \mathrm{M}$ carbachol. Stimulation (20-nC, at arrow) evokes only a small epileptiform burst that does not trigger SD. Lower trace: antagonism of carbachol's action by $1 \mu \mathrm{M}$ atropine. In the presence of carbachol plus atropine, stimulation at $5-\mathrm{nC}$ evokes a response similar to control. Downward deflections are voltage responses to a $0.5-\mathrm{nA}$ current pulse. Resting potential was $-81 \mathrm{mV}$ throughout the recording. $\mu \mathrm{M}$ (Fig. 1; rightmost traces), the amplitude of the depolarizing current pulse needed to evoke an action potential was reduced, and there was an increase in input resistance, as measured by the hyperpolarizing current pulse. At concentrations of $5-50 \mu \mathrm{M}$, carbachol increased input resistance by $17 \%$ from 36.6 to $42.8 \mathrm{M} \Omega$. This increase was significant ( $t=3.6$; $P>0.005$ ).

After application of picrotoxin to neocortical slices from rats 9-14 days of age, electrical stimulation in layer IV evoked paroxysmal activity consisting of $10-$ to 30 -s paroxysms of repetitive spike discharges, as described previously ${ }^{9,10}$. Intracellular recordings demonstrate that such paroxysms were associated with a membrane depolarization and superimposed action potential discharges, as shown in Fig. 2A. In the presence of $50 \mu \mathrm{M}$ picrotoxin, a 10-nC stimulus evoked an epileptiform discharge. After exposure to $10 \mu \mathrm{M}$ carbachol, the same stimulus was ineffective (Fig. 2B). Increasing the stimulus to $12.5 \mathrm{nC}$ evoked only a small response that consisted of two action potentials riding on a membrane depolarization. When a burst response similar to that seen in control conditions was finally evoked in the presence of carbachol, using a $15-\mathrm{nC}$ stimulus, the depolarizing response was increased in amplitude. These effects were reversible upon washing (Fig. 2C) and could be reproduced with reintroduction of carbachol (Fig. 2D). The effects of carbachol were antagonized by $1 \mu \mathrm{M}$ atropine (not shown). Similar results were obtained in 6 additional 
neurons from 6 other slices.

After exposure to picrotoxin, stimulation in neocortical slices from 15- to 21-day-old animals evoked bursts of epileptiform spike discharges that triggered an episode of spreading depression (SD) ${ }^{9}$. An intracellular recording obtained during such an event is shown in the upper trace of Fig. 3. At a resting potential of $-81 \mathrm{mV}$, stimulation in layer IV triggers a membrane depolarization associated with an action potential discharge and a decrease in input resistance. This activity ceases, and the membrane starts to repolarize, as observed in the 9- to 14-day-old animals. However, there is an incomplete recovery, and additional discharges subsequently appear, followed by a large depolarization associated with a virtual loss of measurable input resistance. The neuron slowly repolarizes. During exposure to 50 $\mu \mathrm{M}$ carbachol, frequent small epileptiform discharges were observed. However, orthodromic stimulation (Fig. 3; middle trace, arrow), at an intensity 4 times greater than in control conditions, evokes only a short epileptiform response in the presence of carbachol. SD-like events were not recorded in this neuron when carbachol was present. Atropine antagonized the effects of carbachol (Fig. 3; lower trace). Suppression or elimination of SD was seen in 6 additional neurons in slices from animals ranging in age from 15 to 21 days.

The results of the present series of experiments indicate that the cholinergic agonist carbachol has several effects on neurons in the immature rat neocortex. It alters the basic electrical properties of cortical neurons and changes the pattern of epileptiform activity observed after application of convulsant drugs. Carbachol's most consistent effect on intrinsic membrane properties was to cause a reduction in threshold for action potential generation and an increase in the frequency of firing evoked by suprathreshold current pulses. Such changes were seen with carbachol concentrations as low as $5 \mu \mathrm{M}$. At concentrations greater than $5 \mu \mathrm{M}$, we observed small, but significant, changes in input resistance without changes in the resting membrane potential. These results suggest that the first effect of carbachol is to change conductances activated by depolarization. The changes we observed could arise as a result of decreased in potassium conductances, as reported in the neocortex ${ }^{24}$ and a variety of other pre- parations (e.g. hippocampus ${ }^{1.13 .22}$; sympathetic ganglion ${ }^{28} ;$ myenteric neurons ${ }^{27}$ ), or enhancement of inward currents 5 . Our results do not allow discrimination between these alternatives but do demonstrate the existence of a significant cholinergic modulatory system in the neonatal period.

In the present study, carbachol had both facilitory and suppressive effects on epileptiform activity in slices of immature rat neocortex. Modulation of epileptiform and normal evoked synaptic activity has been a commonly reported action of cholinomimetics in the mature nervous system. In the hippocampus, extracellular field discharges are enhanced by focal application of $\mathrm{ACh}^{16.33}$. This excitatory effect on normal synaptic transmission is due in part

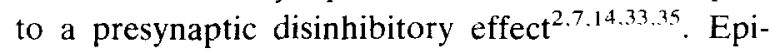
leptiform field bursts in the hippocampus, induced either by lowering extracellular calcium ${ }^{8}$ or by application of penicillin ${ }^{16}$, increase in frequency after exposure to ACh. Similarly, spontaneously released $\mathrm{ACh}$ can augment epileptiform discharges in the neocortex in vivo ${ }^{4}$. It is unlikely that the facilitory effects of carbachol on epileptiform discharges observed here resulted from a disinhibitory action, since all recordings were made in the presence of picrotoxin, a drug known to effectively antagonize chloride-dependent inhibition. It is more likely that the enhanced depolarization underlying the epileptiform bursts is a consequence of the changes we observed in basic electrical properties. Assuming that the epileptiform bursts are mediated by a synaptic input ${ }^{6,15}$, a reduction in outward potassium currents would give rise to an apparent increase in the depolarization evoked by a synaptic current. Likewise, an increase in neuronal input resistance would amplify synaptic inputs. The lack of a significant effect of carbachol on the duration of epileptiform activity suggests that this parameter may not be governed by intrinsic membrane properties but by the synaptic inputs responsible for triggering the discharge.

The carbachol-induced increase in threshold for evoked epileptiform events may be attributable to a presynaptic inhibitory effect. Muscarinic receptors are present on excitatory synaptic terminals in the neocorte $\mathrm{x}^{34}$, and in vivo studies have suggested that cholinergic inputs to the cortex may block activity of extrinsic afferents via presynaptic inhibition ${ }^{29}$. Re- 
duction of excitatory postsynaptic potentials via presynaptic inhibition would result in a loss of excitation and synchronization in the neuronal population, an effect likely to reduce the probability of epileptiform activity ${ }^{32}$.

1 Benardo, L.S. and Prince, D.A., Ionic mechanisms of cholinergic excitation in mammalian hippocampal pyramidal cells, Brain Res., 249 (1982) 333-344.

2 Ben-Ari, Y., Krnjevic, K., Reinhardt, W. and Ropert, N., Intracellular observations on the disinhibitory action of acetylcholine in the hippocampus, Neuroscience, 6 (1981) 2475-2484.

3 Donoghue, J.P. and Carroll, K.L., Cholinergic modulation of sensory responses in rat primary somatic sensory cortex, Brain Res., 408 (1987) 367-371

4 Ferguson, J.H. and Jasper, H.H., Laminar DC studies of acetylcholine-activated epileptiform discharge in cerebral cortex, Electroencephalogr. Clin. Neurophysiol., 30 (1971) 377-390.

5 Gähwiler, B.H. and Dreifuss, J.J., Multiple actions of acetylcholine on hippocampal pyramidal cells in organotypic explant cultures, Neuroscience, 7 (1982) 1243-1256.

6 Gutnick, M.J., Connors, B.W. and Prince, D.A., Mechanisms of neocortical epileptogenesis, $J$. Neurophysiol., 48 (1982) 1321-1335.

7 Haas, H.L. Cholinergic disinhibition in hippocampal slices of the rat, Brain Res., 233 (1982) 200-204.

8 Haas, H.L., Jefferys, J.G.R., Slater, N.T. and Carpenter, D.O., Modulation of low calcium induced field bursts in the hippocampus by monoamines and cholinomimetics, Pflügers Arch., 400 (1984) 28-33.

9 Hablitz, J.J., Spontaneous ictal-like discharges and sustained potential shifts in the developing rat neocortex, $J$. Neurophysiol., 58 (1987) 1052-1065.

10 Hablitz, J.J. and Heinemann, J.J., Extracellular $\mathrm{K}^{+}$and $\mathrm{Ca}^{2+}$ changes during epileptiform discharges in the immature rat neocortex, Dev. Brain Res., 36 (1987) 299-303.

11 Hablitz, J.J. and Sutor, B., Cholinergic modification of epileptiform discharges in the developing rat neocortex, Neuroscience, 22 (1987) S196.

12 Hablitz, J.J. and Sutor, B., Cellular properties of convulsant-treated neocortical neurons in the rat during postnatal development. In P. Kellaway and J.L. Noebels (Eds.), Problems and Concepts in Developmental Neurophysiology, Johns Hopkins Univ. Press, Baltimore, in press.

13 Halliwell, J.V. and Adams, P.R., Voltage-clamp analysis of muscarinic excitation in hippocampal neurons, Brain Res., 250 (1982) 71-92.

14 Hounsgaard, J., Presynaptic inhibitory effect of acetylcholine in area CA1 of the hippocampus, Exp. Neurol., 62 (1978) 787-797.

15 Johnston, D. and Brown, T.H., Giant synaptic potential hypothesis for epileptiform activity, Science, 211 (1981) 294-297.

16 Kriegstein, A.R., Suppes, T. and Prince, D.A., Cholinergic enhancement of penicillin-induced epileptiform discharges in pyramidal neurons of the guinea pig hippocampus, Brain Res., 266 (1983) 137-142.

17 Kriegstein, A.R., Suppes, T. and Prince, D.A., Cellular
This work was supported by National Institutes of Health Grants NS22373 and NS11535, by Deutsche Forschungsgemeinschaft Grant Su 104/1-1, and by a Fellowship Award from the Max Kade Foundation to B.S.

and synaptic physiology and epileptogenesis of developing rat neocortical neurons in vitro, Dev. Brain Res., 34 (1987) $161-171$

$18 \mathrm{Krnjevic,} \mathrm{K}$. and Phillis, J.W., Acetylcholine-sensitive cells in cerebral cortex, J. Physiol. (Lond.), 166 (1963) 296-327.

19 Krnjevic, K., Pumain, R. and Renaud, L., The mechanism of excitation by acetylcholine in the cerebral cortex, $J$. Physiol. (Lond.), 215 (1971) 247-268.

20 Lamour, Y., Dutar, P. and Jobert, A., Excitatory effect of acetylcholine on different types of neurons in the first somatosensory neocortex of the rat: laminar distribution and pharmacological characteristics, Neuroscience, 7 (1982) 1483-1494.

21 Lamour, Y., Dutar, P. and Jobert, A., A comparative study of two populations of acetylcholine-sensitive neurons in rat somatosensory cortex, Brain Res., 289 (1983) $157-167$.

22 Madison, D.V., Lancaster, B. and Nicoll, R.A., Voltage clamp analysis of cholinergic action in the hippocampus, $J$ Neurosci., 7 (1987) 733-741.

23 McCormick, D.A., Connors, B.W., Lighthall, J.W. and Prince, D.A., Comparative electrophysiology of pyramidal and sparsely spiny stellate neurons of the neocortex, $J$. Neurophysiol., 54 (1985) 782-806.

24 McCormick, D.A. and Prince, D.A., Two types of muscarinic responses to acetylcholine in mammalian cortical neurons, Proc. Natl. Acad. Sci. U.S.A., 82 (1985) 63446348.

25 McLennan, H. and Hicks, T.P., Pharmacological characterization of the excitatory cholinergic receptors of rat central neurons, Neuropharmacology, 17 (1978) 329-334.

26 Metherate, R., Tremblay, N. and Dykes, R.W., Acetylcholine permits long-term enhancement of neuronal responsiveness in cat primary somatosensory cortex, Neuroscience, 22 (1987) 75-81.

27 North, R.A. and Tokimasa, T., Depression of calciumdependent potassium conductance of guinea-pig myenteric neurones by muscarinic agonists, J. Physiol. (Lond.), 342 (1983) 253-266.

28 Pennefather, P., Lancaster, B., Adams, P.R. and Nicoll, R.A., Two distinct Ca-dependent $\mathrm{K}$ currents in bullfrog sympathetic ganglion cells, Proc. Natl. Acad. Sci. U.S.A., 82 (1985) 3040-3044.

29 Sikes, R.W. and DeFrance, J.F., Cholinergic modulation of mediodorsal thalamic input into cingulate cortex, Brain Res., 345 (1985) 327-331.

30 Stone, T.W., Cholinergic mechanisms in the rat somatosensory cerebral cortex, J. Physiol. (Lond.), 225 (1972) 485-499.

31 Strejckova, A., Mares, P. and Raevsky, V., Changes in activity of cortical neurons induced by acetylcholine in adult and young rats, Exp. Neurol., 98 (1987) 555-562.

32 Traub, R.D. and Wong, R.K.S., Penicillin-induced epileptiform activity in the hippocampal slice: a model of 
synchronization of $\mathrm{CA}_{3}$ pyramidal cell bursting, Neuroscience, 6 (1981) 223-230.

33 Valentino, R.J. and Dingledine, R., Presynaptic inhibitory effect of acetylcholine in the hippocampus, J. Neurosci., 7 (1981) 784-792.

34 Vogt, B.A., Afferent specific localization of muscarinic acetylcholine receptors in cingulate cortex, J. Neurosci., 4 (1984) 2191-2199.

35 Yamamoto, C. and Kawai, N., Presynaptic action of acetylcholine in thin sections from the guinea pig dentate gyrus in vitro, Exp. Neurol., 19 (1967) 176-187. 